\title{
Paraneoplastic Orthostatic Tremor Associated with Small Cell Lung Cancer
}

\author{
H.J. Gilhuis ${ }^{a}$ H.J. van Ommen ${ }^{a}$ B.J.M. Pannekoek ${ }^{b}$ P.A.E. Sillevis Smitt ${ }^{c}$ \\ Departments of a Neurology and ${ }^{b}$ Pulmonology, Reinier de Graaf Group Hospital, Delft, and \\ ${ }^{\mathrm{c}}$ Department of Neurology, Erasmus University Medical Centre, Rotterdam, The Netherlands
}

Dear Sir,

Paraneoplastic neurological syndromes (PNS) are disorders associated with cancer that are not directly related to the tumour or its metastases. Presumably, immunological factors play an important role in the aetiology of PNS. Ectopic expression of neuronal antigens by the tumour provokes an immune reaction that subsequently cross-reacts with similar antigens in the nervous system $[1,2]$. Often, but not always, the serum of patients with PNS contains paraneoplastic antineuronal antibodies, such as the anti$\mathrm{Hu}$ antibody. In PNS, all parts of the nervous system may be affected resulting in a wide variety of presenting symptoms. We describe for the first time a patient who developed severe orthostatic tremor (OT) as the sole presenting paraneoplastic manifestation of small cell lung cancer (SCLC). Treatment with chemotherapy was followed by marked clinical improvement.

\section{Case Report}

A 55-year-old, otherwise healthy woman was referred for a severe tremor of the head, arms and legs, gradually becoming worse within a week. The tremor was induced by standing and did not disappear while walking. However, the symptoms disappeared when she sat or laid down. She had no history of drug abuse or use of medication, but reported a 40-pack-year smoking history. Neurological examination re- vealed a wild and disabling shaking of the arms, legs and head while attempting to stand or walk. The shaking had a frequency of 3-5 Hz. When she lay down, the examination was completely normal. No other neurological symptoms were present. Routine laboratory tests (including thyroid functions, calcium and phosphate), EEG and MRI of the brain were normal. Six weeks after the beginning of symptoms, she became progressively dyspnoeic and lost weight. An SCLC in the right upper lobe with lymph node and liver metastases was diagnosed. Anti-Hu antibodies were present in serum (titre of 1:3,200). A few days after the initiation of chemotherapy, the shaking gradually disappeared, and within a week only a slight tremor of the hands remained. She was able to stand and walk again till she died of respiratory failure 9 months later.

\section{Discussion}

We present a patient with subacute onset, disabling OT, who was subsequently diagnosed with SCLC. According to the recently published diagnostic guidelines for PNS [3], the aetiology of the OT in our patient is definitely paraneoplastic because of its close temporal relation to the diagnosis of SCLC, the presence of anti-Hu antibodies and the regression of symptoms after chemotherapy.
OT is a rare clinical syndrome in which a rapid (14-16 Hz) regular lower limb tremor causes unsteadiness on standing that is relieved when sitting or walking. OT is generally considered to be an idiopathic disorder (primary OT), although it has also been described in patients with Parkinson's disease, hydrocephalus, pontine lesions, head trauma and cerebellar degeneration [4-6]. A positron emission tomography study in primary OT suggested increased blood flow in the cerebellum bilaterally and in the thalamus and lentiform nuclei contralateral to an arm with $16-\mathrm{Hz}$ tremor, suggesting involvement of the cerebellum [7].

In contrast to primary OT, the tremor in our patient had a frequency of $3-5 \mathrm{~Hz}$ and did not decrease on walking. Also, this tremor involved all limbs and the head, and was so disabling that our patient was confined to her bed. In our patient, the symptoms were caused by an anti-Hu-associated paraneoplastic syndrome, probably affecting the brainstem and/or cerebellum.

The most common paraneoplastic syndromes associated with anti-Hu antibodies include sensory neuropathy (54-55\%), cerebellar degeneration (10-22\%), limbic encephalitis $(9-15 \%)$ and brainstem encephalitis $(16 \%)[1,2]$. The most prevalent underlying neoplasm is SCLC $[1,2]$. So far, OT has not been reported as an anti-Hu-antibody-associated paraneoplastic syndrome.

\section{KARGER}

Fax +4161306 1234 E-Mail karger@karger.ch www.karger.com
(C) 2005 S. Karger AG, Basel 0014-3022/05/0544-0225\$22.00/0

Accessible online at: www.karger.com/ene
Dr. H. Jacobus Gilhuis

Department of Neurology, Reinier de Graaf Group Hospital

PO Box 5011

NL-2600 GA Delft (The Netherlands)

Tel. +31 1526037 50, Fax +31 1526035 48, E-Mail gilhuis@rdgg.nl 
The exact role of anti-Hu antibodies in the pathogenesis of PNS remains unclear.

Pathological examination of the nervous system generally shows neuronal cell loss and inflammatory infiltrates in affected areas with inflammatory infiltration in the interstitial and perivascular spaces [8-10].

Although paraneoplastic cerebellar degeneration and brainstem encephalitis are usually accompanied by signs of a multifocal encephalomyelitis [1], this tremor was the sole paraneoplastic symptom. Interestingly, the symptoms improved dramatically after chemotherapy. Neurological improvement is rarely seen in PNS, with the exception of patients with limbic encephalitis [2]. In our patient, early chemotherapy may have limited irreversible cerebellar damage.

\section{Acknowledgement}

The authors thank Dr. J. Pomp for her critical comments.
References

1 Graus F, Keime-Guibert F, Rene R, Benyahia B, Ribalta T, Ascaso C, Escaramis G, Delattre JY: Anti-Hu-associated paraneoplastic encephalomyelitis: analysis of 200 patients. Brain 2001;124:1138-1148.

2 Sillevis Smitt P, Grefkens J, de Leeuw B, van den Bent M, van Putten W, Hooijkaas H, Vecht C: Survival and outcome in 73 anti-Hu positive patients with paraneoplastic encephalomyelitis/sensory neuronopathy. J Neurol 2002;249:745-753.

3 Graus F, Delattre JY, Antoine JC, et al: Recommended diagnostic criteria for paraneoplastic neurological syndromes. J Neurol Neurosurg Psychiatry 2004;5:1135-1140.

4 Gerschlager W, Munchau A, Katzenschlager R, Brown P, Rothwell JC, Quinn N, Lees AJ, Bhatia KP: Natural history and syndromic associations of orthostatic tremor: a review of 41 patients. Mov Disord 2004;19:788-795.

5 Deuschl G, Bain P, Brin M: Consensus statement of the Movement Disorder Society on Tremor. Ad Hoc Scientific Committee. Mov Disord 1998;13(suppl 3):2-3.
6 Benito-Leon J, Rodriguez J, Orti-Pareja M, Ayuso-Peralta L, Jimenez-Jimenez FJ, Molina JA: Symptomatic orthostatic tremor in pontine lesions. Neurology 1998;51:923.

7 Wills AJ, Thompson PD, Findley LJ, Brooks DJ: A positron emission tomography study of primary orthostatic tremor. Neurology 1996; 46:747-752.

8 Denny-Brown D: Primary sensory neuropathy with muscular changes associated with carcinoma. J Neurol Neurosurg Psychiatry 1948; 11:73-87.

9 Jean WC, Dalmau J, Ho A, Posner JB: Analysis of the IgG subclass distribution and inflammatory infiltrates in patients with an anti-Hu associated paraneoplastic encephalomyelitis. Neurology 1994;44:140-147.

10 Bernal F, Graus F, Pifarre A, Saiz A, Benyahia $\mathrm{B}$, Ribalta T: Immunohistochemical analysis of anti-Hu associated paraneoplastic encephalomyelitis. Acta Neuropathol 2002;103:509515. 